\title{
Матричное тепловидение нового поколения в химии и химической физике
}

\author{
Б.Г. Вайнер ${ }^{1,2}$ \\ ${ }^{1}$ Институт физики полупроводников им. А.В. Ржанова СО РАН, \\ Новосибирск, 630090, пр-т Ак. Лаврентьева, 13 \\ ${ }^{2}$ Новосибирский государственный университет, Новосибирск, 630090, ул. Пирогова, 2 \\ тел: +7 (383) 330-7781, эл. почта: BGV@isp.nsc.ru
}

DOI 10.34077/RCSP2021-89

Большинство химических реакций сопровождается выделением теплоты. При этом, как отражалось в литературе, наблюдаемые температурные изменения способны служить количественным показателем химических процессов [1]. Более того, информация о температуре в ряде случаев является решающей для понимания термодинамики и кинетики реакций [2].

Уникальные технические возможности современной ИК термографии (количественного матричного тепловидения), позволяющие без физического вмешательства в объект исследования проводить температурные измерения с чувствительностью порядка $0.01{ }^{\circ} \mathrm{C}$ и выше, реализовать временное разрешение порядка 0.01 с и короче, дают основания считать этот метод одним из наиболее подходящих для химических приложений, в том числе, для адсорбции и катализа. Благодаря современной доступности и своим беспрецедентным свойствам тепловизионный метод исследования по сути породил новое экспериментальное направление в изучении разнообразных экзотермических и эндотермических процессов, протекающих в на поверхности твердых тел. Высокая эффективность применения тепловизионного подхода для этой цели была обоснована и продемонстрирована автором настоящего доклада в недавнем обзоре [3].

В представленном докладе приведены разнообразные примеры исследований, проведенных в ИФП СО РАН при тепловизионном изучении процессов адсорбции и десорбции молекул газа на твердых поверхностях разной физико-химической природы. Также показаны тепловые эффекты для случаев, когда тепловизор был использован в ходе исследования каталитических процессов окисления окиси углерода до $\mathrm{CO}_{2}$. Значимость последних работ состоит, в первую очередь, в том, что было надежно установлено, что высокочувствительное матричное тепловидение позволяет на количественном уровне изучать динамику каталитических процессов, протекающих уже при комнатной, а не более высокой, что характерно для катализа, температуре, а потому порождает новый информационный канал для этой области знаний.

Эксперименты проводились на оригинальном автоматизированном комплексе, созданном специально для данных работ. Изучаемые высокодисперсные образцы помещались в реактор с входным окном, прозрачным в ИК области спектра, в виде библиотеки, состоящей из 15 ячеек (рис. 1), что позволяло изучать свойства одновременно 15 разнотипных образцов в одних и тех же физикохимических условиях. Такой подход кардинально увеличивает производительность измерений и

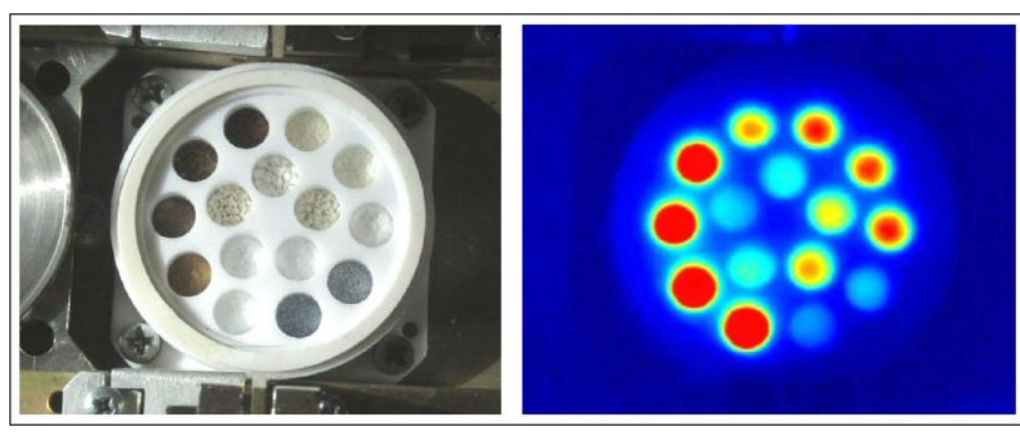

Рис. 1. Термограмма библиотеки емкостью 15 ячеек с разными загруженными в нее образцами, имеющими отличающуюся друг от друга сорбционную способность поверхности. Измерено матричным тепловизором ТКВр-ИФП/СВИТ (ИФП CO PAH).

достоверность получаемых результатов в сравнительных исследованиях.

Показано, что современная высокоскоростная и высокочувствительная количественная ИК термография является новым высокоперспективным инструментом экспериментальных исследований в области химии и химической физики.

\section{Лumepamypa}

[1] S. Taylor, P. Morken P. // Science. 1998. Vol. 280. P. 267-270.

[2] H. Kulla et al. // Angewandte Chem. Int. Ed. 2018. Vol. 57. P. 5930-5933.

[3] B.G.Vainer // ChemPlusChem. 2020. Vol. 85. P. 1438-1454. 